\title{
CALVÁRIO E PORRES DO PINGENTE AFONSO HENRIQUE DE LIMA BARRETO, DE JOÃO ANTÔNIO E O NOVO ROMANCE HISTÓRICO BRASILEIRO
}

\author{
CALVÁRIO E PORRES DO PINGENTE AFONSO HENRIQUE DE LIMA BARRETO, BY \\ JOÃO ANTÔNIO AND THE NEW BRAZILIAN HISTORICAL NOVEL
}

Bruno Marques Duarte ${ }^{1}$

\section{Resumo}

O presente artigo analisa a composição do romance histórico Calvário e porres do pingente Afonso Henrique de Lima Barreto, de João Antônio, no âmbito da ficção histórica brasileira contemporânea. Nesse exame, objetiva-se apontar as principais inovações que essa obra, em particular, ocasionou na estrutura do novo romance histórico brasileiro.

Palavras-chave: Romance histórico; João Antônio; Lima Barreto; História da Literatura.

\begin{abstract}
This paper analyzes the composition of the historical novel Calvário e porres do pingente Afonso Henrique de Lima Barreto, by João Antônio, in the field of the Brazilian contemporary historical fiction. The purpose of this examination is to indicate the main innovations that this work has caused in the structure of the new Brazilian historical novel.
\end{abstract}

Keywords: Historical novel; João Antônio, Lima Barreto, History of Literature.

\section{Considerações preliminares}

As relações entre a história e a literatura estão presentes desde o início da própria literatura ocidental. Podemos observar, na Ilíada, que Homero se apropria dos eventos passados pertencentes à tradição oral grega, para narrar poeticamente uma guerra possivelmente ocorrida em Troia. A partir desse momento, a ficção e a história passaram a desenvolver uma série de entrecruzamentos através dos séculos, ora em ocasiões mais produtivas, ora em períodos de declínio.

É apenas no século XIX que o romance histórico se consolida como um gênero autônomo e portador de peculiaridades próprias estabelecidas pelas obras de Walter Scott.

\footnotetext{
${ }^{1}$ Mestrado em Letras pela Universidade Federal do Rio Grande-FURG (2011) e Graduação em Licenciatura em História pela Universidade Federal do Rio Grande-FURG (2007).Doutorando pela Universidade Federal do Rio Grande- FURG.E-mail: brunomd@hotmail.com
} 
Nessa época, a literatura era escrita predominantemente pelas características do Romantismo; desse modo, o novo gênero desempenhava uma função fundamental, pois narrava o passado dos povos que se afirmavam como nações soberanas e culturalmente independentes.

$\mathrm{Na}$ literatura brasileira, observam-se os mesmos influxos desse movimento literário no projeto ambicioso de nacionalidade concebido por José de Alencar, o qual inaugura o romance histórico brasileiro com as obras As minas de prata (1862) e A guerra dos mascates (1873). Alencar escreve os seus romances históricos fundamentados, evidentemente, pelos paradigmas estabelecidos pelos europeus, sobretudo aqueles constituídos por Scott. Tais particularidades foram analisadas posteriormente por Georg Lukács na obra $O$ romance histórico, de 1936, considerada até os dias atuais referência de estudos sobre o gênero.

Do século XIX ao XX, o romance histórico passa por diversas modificações, tanto de ordem formal, como de conteúdo e ideologia. As transformações foram sentidas, de tal modo, que a crítica literária registra o conceito de novo romance histórico para designar o conjunto de obras ficcionais históricas produzidas, especialmente, a partir dos anos de 1970. Para Seymour Menton, essas transformações vieram através do romance histórico O reino deste mundo (1949), de Alejo Carpentier, que rompe com o tradicional modelo de romances históricos produzidos até então na América Latina (MENTON, 1993, p. 38).

Compreende-se, portanto, que a partir da metade do século XX, a literatura histórica da América Latina apresenta um conjunto de romances que tem por intenção problematizar a história oficial latino-americana. Essas evidências literárias proporcionaram uma série de mudanças significativas na composição do romance histórico. As principais características desse conceito foram estudadas e sintetizadas por Menton, em 1993, na obra La nueva novela histórica de la América Latina, 1979-1992.

Seymour Menton - ao lado de Linda Hutcheon, Fernando Aínsa e outros - é um dos principais acadêmicos a examinar os novos traços do romance histórico na América Latina. Além disso, o autor procurou sistematizar tais produções a partir das características gerais que essas obras apresentam. Desse modo, Menton elabora uma lista de vários romances históricos publicados no decorrer do século XX e a divide em duas modalidades: na primeira, têm-se os romances históricos considerados tradicionais; na segunda, observam-se as narrativas históricas que contêm as particularidades que Menton identifica como novo romance histórico. Dentre os cinquenta e oito romances históricos dessa segunda classificação, sete são brasileiros. As obras mencionadas são: Galvez imperador do Acre (1976), Mad Maria (1984) e O primeiro brasileiro (1986), todas de Márcio Souza; Em liberdade (1981), de Silviano Santiago; Viva o povo brasileiro (1984), de João Ubaldo Ribeiro; A casca da serpente (1989), 
de José J. Veiga; e Memorial do fim: a morte de Machado de Assis (1991), de Haroldo Maranhão.

Para os leitores identificarem o grau de ruptura do romance histórico clássico para o novo romance histórico, Menton delineia seis peculiaridades que os novos romances históricos, de um modo geral, apresentam na sua composição. Transcreverei essas seis características para posteriormente examinar a obra Calvário e porres do pingente Afonso Henrique de Lima Barreto, de João Antônio. Temos as seguintes características sintetizadas pelo referido autor:

1. A subordinação, em diferentes graus, da reprodução mimética de um determinado período histórico para a apresentação de algumas ideias filosóficas aplicáveis a períodos do passado, presente e futuro. As ideias que se destacam são as da impossibilidade de conhecer a verdade histórica ou a realidade; o caráter cíclico da história e, parodicamente, o caráter imprevisível desta, o que significa que os eventos mais inesperados e mais surpreendentes podem ocorrer.

2. A distorção consciente da história, mediante omissões, exageros e anacronismos.

3. A ficcionalização de personagens históricos bem conhecidos, ao contrário da fórmula de Scott, cujos protagonistas são fictícios.

4. A metaficção ou os comentários do narrador sobre o processo de criação.

5. A intertextualidade.

6. Os conceitos bakhtinianos: o dialogismo, a carnavalização, a paródia e a heteroglossia (MENTON, 1993, p. 42-46).

Conforme adverte Menton, o que define o novo romance histórico não é necessariamente a presença dessas seis características (1993, p. 42). Na verdade, alguns romances apresentam quase todos esses elementos, porém, em outros, a presença de tais traços é mais sutil. Pode acontecer, também, de se verificar apenas uma ou duas das seis características apontadas.

Segundo Linda Hutcheon, na Poética do pós-modernismo (1991), essas novas modalidades narrativas se inserem no âmbito do pós-modernismo, uma vez que elas apresentam em si um "fenômeno contraditório, que usa e abusa, instala e depois subverte os próprios conceitos que desafia”, seja na historiografia, na literatura, ou nas demais manifestações artísticas (1991, p. 19). A autora concebe o conceito de metaficção historiográfica para definir os "romances famosos e populares que, ao mesmo tempo, são intensamente autorreflexivos e mesmo assim, de maneira paradoxal, também se apropriam de acontecimentos e personagens históricos” (HUTCHEON, 1991, p. 21). 
Hutcheon aponta que a "metaficção historiográfica não pretende reproduzir acontecimentos, mas, em vez disso, orientar-nos para os fatos, ou para novas direções a tomar, para que pensemos sobre os acontecimentos” (1991, p. 198). De acordo com a autora, geralmente, nessas obras ocorre a presença de recursos estilísticos, tais como a intertextualidade, o discurso da História, a paródia e o pastiche. Hutcheon argumenta que é a incidência constante dessas características que constitui a poética do pós-modernismo, uma vez que essas particularidades também estão presentes em períodos anteriores à própria modernidade.

No livro O romance histórico brasileiro contemporâneo (1975-2000), Antônio Esteves acrescenta algumas obras que se enquadram nas teorias de Menton, e no que Linda Hutcheon conceitua de metaficção historiográfica: Catatau (1975), de Paulo Leminski; Cálvario e porres do pingente Afonso Henriques de Lima (1977), de João Antônio; e o conto “H.M.S. Cormorant em Paranaguá”, de O cobrador (1979), de Rubem Fonseca.

Portanto, a partir desse referencial teórico, examinaremos as peculiaridades composicionais do referido romance de João de Antônio. Do mesmo modo, observaremos quais as características enunciadas que a obra apresenta. Caso seja admissível, sublinharemos a inovação e/ou a repercussão que esse romance representa no âmbito da tradição literária brasileira, especialmente, se o classificarmos como um romance histórico de características contemporâneas. Mas antes, exploraremos o contexto de produção de Calvário e porres do pingente Afonso Henriques de Lima.

\section{João Antônio e o projeto sobre Lima Barreto}

João Antônio estreou na literatura brasileira pelo gênero do conto com a publicação de Malagueta, perus e bacanaço, em 1963. Essa obra obteve reconhecimento imediato pela crítica literária, pois significou na época a consagração do autor como promissor contista da literatura nacional. No ano posterior, ele recebeu o $6^{\circ}$ prêmio Jabuti na categoria Contos / Crônicas / Novelas. Além disso, em 1977, o referido conto foi adaptado para o cinema sob o título de $O$ jogo da vida, cujo roteiro é também assinado pelo próprio João Antônio.

A partir de 1974, ano que marca a publicação da segunda edição do premiado Malagueta, Perus e Bacanaço, o autor passa a escrever em todos os seus livros a dedicatória para Lima Barreto. A mais extensa dedicatória destinada ao seu preferido escritor ocorre em Ô Copacabana, de 1978: “A Afonso Henriques de Lima Barreto / nunca bastante lembrado / pioneiro / captador de bandalheiras / e denunciador / desconcertante / consagro / com a devida 
humildade”. Essas dedicatórias traduzem, no geral, a admiração que João Antônio tinha pelo escritor de Triste fim de Policarpo Quaresma, e também expõe o quanto ele era leitor assíduo da obra barretiana.

A estima que João Antônio expressava por Lima Barreto se confirma plenamente na entrevista com Flávio Aguiar no jornal Movimento, de 1975. Nesta, conta-nos que tinha uma profunda admiração pelo escritor pré-modernista, e ainda trabalhou num projeto literário sobre Lima Barreto que se encontrava recentemente concluído. Assim, João Antônio concebe o romance Calvário e porres do pingente Afonso Henrique de Lima Barreto, descrito como uma grande homenagem ao escritor pré-modernista. João Antônio ainda salienta nessa entrevista que em toda a extensão do referido trabalho não há uma única palavra de sua autoria. No entanto, o projeto o conduziu a ler toda a obra de Lima Barreto, inclusive suas correspondências e documentos pessoais.

Esse reconhecimento público de devoção fez com que a Folha de São Paulo, em 1995, deliberasse chamar João Antônio para escrever a introdução de uma coletânea das crônicas de Lima Barreto. O texto introdutório, de título “Conheçamos Lima Barreto, um descobridor do Brasil”, discorre sobre as qualidades literárias do seu cultuado mestre, em especial de suas crônicas. Essa introdução tinha o intuito de promover a manutenção da presença do escritor no cânone, e as suas crônicas são reflexões a propósito da sociedade e do espaço do Rio de Janeiro, em particular, as pessoas de classe baixa.

Retomando o exposto, nessa sucinta exposição sobre a vida literária de João Antônio, vimos que o escritor leu todas as obras de Lima Barreto juntamente com suas correspondências e documentos pessoais. Nisso reside a admiração que João Antônio tinha por Lima Barreto, resultando na produção do romance Calvário e porres do pingente Afonso Henrique de Lima Barreto, que reconstrói ficcionalmente momentos da vida do estimado escritor.

\section{A composição de Calvário e porres do pingente Afonso Henrique de Lima Barreto}

O romance Calvário e porres do pingente Afonso Henrique de Lima Barreto de João Antônio foi publicado em 1977, pela Editora Civilização Brasileira, na Coleção Vera Cruz de Literatura Brasileira. O livro, até o presente momento, não teve mais nenhuma publicação, sendo difícil encontrá-lo até mesmo em sebo, inclusive nos on-line. De fato, isso parece confirmar o lugar desprestigiado que Lima Barreto ocupava no cenário da crítica literária do período, ou até mesmo João Antônio no âmbito do gênero romance. Do mesmo modo, 
podemos concluir que a obra não obteve o horizonte de expectativas suficiente de leitores para garantir sua posteridade; por consequência, a sua circulação permanece comprometida.

O romance é organizado em três partes assim dispostas no sumário: "Lima Barreto, pingente” / "Nota prévia” / “Calvário e porres do pingente Afonso Henriques de Lima Barreto”. Esses três textos reunidos, mais a dedicatória, totalizam noventa páginas, sendo que a primeira parte possui apenas quatro páginas; a segunda somente uma; e a terceira que é o cerne do romance, possui setenta e uma. Antes da primeira parte, há duas dedicatórias: a primeira no canto superior direito da página endereçada "Para DANIEL PEDRO DE ANDRADE FERREIRA - meu filho"; a segunda, no canto inferior direito registra "Consagro / ao talento e ao caráter / e (humildemente) / à atualidade / do / pioneiro aqui reverenciado / AFONSO HENRIQUES DE LIMA BARRETO” (ANTÔNIO, 1977, p. 7). Na contracapa do romance encontra-se a seguinte síntese: “Itinerário arquipoético das andanças, pensares e fazeres de Lima Barreto, o pensamento vivo desse artista, que foi um dos mais sensíveis e mais brasileiros dos nossos escritores”.

O texto introdutório de cunho ensaístico prévio ao romance, de título "Lima Barreto, pingente”, registra alguns episódios biográficos do referido escritor, como data de nascimento, morte e, na sequência, apresenta uma crítica severa sobre a condição póstuma que a obra Barretiana ocupa no âmbito da literatura nacional, em síntese, um lugar menor. Para Antônio, Lima Barreto é “uma espécie de pingente no quadro geral dos nossos valores literários”. O autor argumenta que "tudo em Lima é atual”, e de uma "atualidade alarmante”, porém, hoje, essa atualidade é esquecida (1977, p. 13). Na sequência, Antônio elege os quatro melhores romances de Barreto: Recordações do escrivão Isaías Caminha, Triste fim de Policarpo Quaresma, Numa e Ninfa e Clara dos Anjos; e aponta que alguns contos são fundamentais para quem ambiciona conhecer a literatura brasileira (1977, p. 13-14).

Nessa introdução, João Antônio lamenta severamente a época em que vive ao enunciar que apesar de já termos uma considerada contribuição de análise social do Brasil pelas obras de Lima Barreto, continuamos ainda "sem visão da nossa vida, sem vigor de estudos, sem um critério filosófico ou social seguro” (1977, p. 15). Antônio reivindica a memória de Barreto até mesmo na data de assinatura dessa entrada, 13 de maio de 1976. Além de esta lembrar o nascimento do escritor pré-modernista, em 1881, também se refere à abolição da escravatura, sucedida em 1888. Portanto, a data vincula-se a dois principais objetos discorridos pelo autor na introdução: Lima Barreto e a sociedade brasileira da década de 70 . 
O ensaio introdutório “Lima Barreto, pingente” possui três funções que estão correlacionadas. A primeira é a de apresentar o escritor Lima Barreto, protagonista do romance que se segue, para os leitores. Nesse sentido, o leitor toma conhecimento de algumas qualidades literárias do escritor, tais como a sua sagaz observação e valorização do subúrbio carioca, crítica às instituições, entre outras reflexões. A segunda função consiste em reivindicar uma posição proeminente para Lima Barreto no âmbito da crítica e historiografia literária brasileira. Nesse aspecto, Antônio sugere até uma seleção dos melhores romances do autor. A terceira é a de apresentar subjacente em sua escrita, já nesse primeiro texto, um conceito de literatura que diz respeito a esta ter uma função na sociedade.

Em seguida, temos o texto “Nota prévia”, também assinado por João Antônio, só que dessa vez sem data. A partir desse momento estabelece-se o pacto ficcional, ou seja, o romance. Citaremos o texto na íntegra para esclarecermos a referida hipótese.

\section{NOTA PRÉVIA}

ESTE ROTEIRO dos bares urbanos frequentados pelo amanuense Afonso Henriques de Lima Barreto, me foi passado no Sanatório da Muda da Tijuca, entre maio e junho de 1970, pelo professor Carlos Alberto Nóbrega da Cunha, homem tido e havido como caduco, maníaco e esclerosado. Na mocidade, diretor político do Diário de Notícias, depois subsecretário de O Jornal. Conheceu Lima Barreto em vida e tinha setenta e dois anos quando me deu o depoimento. Os textos em destaque são de e em torno de Lima. Assim, não há aqui uma palavra minha. Como um montador de cinema, tesoura em punho, dei ritmo e respiração ao trabalho alheio. Participei, se muito, na linguagem da versão final do depoimento (ANTÔNIO, 1977, p. 17).

Essa "nota” explica - ficcionalmente ou não - a origem do contexto de produção do romance de João Antônio. Observa-se também a anunciação da intriga do próprio: “roteiro dos bares urbanos frequentados pelo [...] Lima Barreto”. Como se vê, Antônio informa que, em 1970, no Sanatório da Muda da Tijuca, conheceu Carlos Alberto Nóbrega da Cunha, e este lhe proveu um depoimento sobre Lima Barreto, uma vez que o conheceu em vida. Podemos comprovar a veracidade de algumas dessas informações. Uma delas é a de que Antônio foi realmente internado com estresse no referido sanatório naquele ano. O citado professor de português Carlos Alberto Nóbrega da Cunha foi editor de $O$ Jornal e repórter internacional. Além disso, ele conviveu com alguns escritores e intelectuais, entre eles, Monteiro Lobato e Emílio de Menezes, durante o primeiro quartel do século XX.

Apesar de confirmarmos esses dados históricos referentes ao "real”, o suposto depoimento denota graus de ficcionalidade na "Nota prévia”. Não estamos afirmando que o 
depoimento não é verdadeiro ou que não existiu, até porque isso não é possível comprovar e também não é pertinente para o exame da obra, no entanto, o fato de João Antônio levar sete anos para publicar o texto com a voz narrativa do referido depoente chama a atenção, pois o romance somente é publicado em 1977. Portanto, o que constatamos é um plano narrativo que se utiliza da voz de Carlos Alberto Nóbrega da Cunha trabalhada ficcionalmente por João Antônio. Essa hipótese comprava-se na seguinte passagem: “como um montador de cinema, tesoura em punho, dei ritmo e respiração ao trabalho alheio” (ANTÔNIO, 1977, p. 17).

O terceiro texto, de título homônimo ao livro, é composto de 97 partes, de dimensões variáveis. Sendo que 89 dessas partes são elementos textuais, enquanto oito constituem dados não textuais. Os textos são organizados da seguinte forma:

a) 36 partes da voz narrativa do depoimento de Carlos Alberto Nóbrega da Cunha;

b) Sete de Triste fim de Policarpo Quaresma (1915);

c) Seis de Vida e morte de M. J. Gonzaga de Sá (1919);

d) Cinco de Recordações do escrivão Isaías Caminha (1909) e Clara dos anjos (1948);

e) Quatro de Bruzundungas (1923) e Correspondência (1956);

f) Três de Vida urbana (1953) e Diário íntimo (1953);

g) Duas de O homem que sabia javanês (1911), Feiras e mafuás (1953) e Histórias e sonhos (1920);

h) Uma da Correspondência entre Monteiro Lobato e Lima Barreto, Edgard Cavalheiro; comentário de Antônio Torres; Numa e a Ninfa (1915); artigo Recordações do escritor Afonso Henriques de José Nava; episódio relatado por Aldo Borgatti; O Cemitério dos vivos (1953); página da primeira edição de Numa e a Ninfa, revista por Lima Barreto; Dentes negros e cabelos azuis; A vida de Lima Barreto, de Francisco de Assis Barbosa; A Nova Califórnia; fac-símile da primeira página dos originais de A Nova Califórnia; prefácio de Clara dos anjos, escrito por Sérgio Buarque de Holanda.

No meio dessa complexa estrutura têm-se os seguintes dados não textuais:

a) Foto de José Cabral da casa da infância de Lima Barreto, na Ilha do Governador;

b) Fac-símile da capa da primeira edição de Histórias e sonhos;

c) Capa da terceira edição de Triste fim de Policarpo Quaresma, livro de bolso;

d) Capa da terceira edição de Recordações do escrivão Isaías Caminha, livro de bolso; 
e) Charge sobre os personagens de Numa e a Ninfa; caricatura de Lima Barreto, de 1919.

Nota-se que a obra de João Antônio compõe-se de múltiplos textos de diferentes gêneros, tais como romances, diários, correspondências, ilustrações, caricaturas, ensaios, fotos, charges e até uma observação médica extraída do livro de observações clínicas do Instituto de Psiquiatria do Brasil. Todas as partes mencionadas seguem uma regra geral de disposição no romance. Primeiro temos a suposta narrativa de Carlos da Cunha, na sequência surge uma citação entre aspas de alguma obra de Lima ou, então, algum texto crítico. Depois um documento, foto e/ou charge sobre ele. A seguir, novamente um fragmento de Carlos da Cunha, e assim sucessivamente.

As partes intertextuais do romance, que na sua maioria são citações das obras literárias de Lima Barreto, apresentam-se intercaladas com o depoimento de Carlos da Cunha que, sem dúvida, é a narrativa central de Calvário e porres do pingente Afonso Henrique de Lima Barreto. As trinta e seis partes dessa voz costura dos demais fragmentos, inclusive dos elementos não textuais. Essa instância narrativa apresenta-se na forma de narrador testemunha ou homodiegético, e é quem nos conta o referido "itinerário arquipoético" de Lima Barreto pelo Rio de Janeiro. Portanto, é esse o narrador que estabelece a unidade de sentido entre e com os outros narradores dos outros textos literários citados.

O relato de Carlos da Cunha apresenta cerca de dez lugares visitados por Lima Barreto no espaço carioca. O roteiro tem início no bar da Rua Sachet, primeiro boteco do percurso de Barreto, nesse mesmo prédio havia uma livraria pequena, igualmente frequentada pelo referido autor. Segundo o narrador, o escritor só bebia parati, “recusava qualquer outra bebida alcoólica, inclusive cerveja” (ANTÔNIO, 1977, p. 22). Nesse bar havia uma roda de convivência designada de "roda de Cavalcanti”, devido à presença constante de Coelho Cavalcanti, conhecido jornalista e advogado na época, sendo Lima o único suburbano do encontro. Nesse círculo,

falava-se de muita coisa: literatura, opiniões a respeito das últimas obras editadas e [...] em nossas livrarias podia-se adquirir [...] as obras primas dos maiores escritores e pensadores de todos os tempos e de todos os povos [...]. Assim, Lima podia adquirir a cultura larguíssima e sólida que através de suas páginas, como de suas conversas, encantava os ouvintes (ANTÔNIO, 1977, p. 28-29). 
Na saída, Lima tomava a Avenida Rio Branco em direção à Rua do Rosário e passava pela esquina da conhecida Rua do Ouvidor. Às vezes ele entrava na Livraria Garnier e/ou na Livraria Alves, ambas eram próximas. Seguindo, entrava na Rua Largo de São Francisco de Paula, cujo “ambiente era de meetings políticos e, se o orador era bom, Lima ouvia. Não participava, era um observador” (ANTÔNIO, 1977, p. 31). O próximo ponto era os bares do beco do Rosário. Nessa parte Barreto encontrava alguns dos companheiros suburbanos, modestos, funcionários públicos que pertenciam a baixas "carreiras burocráticas por insuficiência de instrução, embora não de inteligência” (ANTÔNIO, 1977, p. 35).

Na saída do bar da Rua do Rosário, Lima e alguns de seus companheiros seguiam para outros bares na Rua da Conceição e na Rua José Maurício com a Rua Buenos Aires. No bar da Rua José Maurício, "Lima parava para uma só talagada e depois se mandava” (ANTÔNIO, 1977, p. 48). O próximo bar visitado pelo escritor encontrava-se situado na lateral da Estação Dom Pedro II. Esse bar era um dos mais conhecidos pontos de encontro no Rio de Janeiro de 1916. Neste, “Lima se demorava e muito porque encontrava funcionários da Central, do Ministério da Guerra, companheiros antigos que faziam do bar um ponto de encontro depois do expediente” (ANTÔNIO, 1977, p. 48). Nos finais de semana, pelo menos até 1919, os encontros aconteciam no Café Canalejas do bairro Engenho Novo, depois no Café Portuense do Méier.

O romance, ao reconstituir o percurso de Barreto pelos bares do Rio de Janeiro, simultaneamente e gradativamente, começa a delinear uma imagem representativa da personalidade do escritor. A narrativa de início tem como objeto o espaço carioca, a descrição física dos bares, nome das ruas, bebidas solicitadas, companheiros de Lima, personalidades históricas da época etc. No entanto, da metade do romance para o final, o narrador passa a colocar a descrição da personalidade de Barreto para o centro da obra. Essa leitura confirmase na seguinte passagem: “o escritor demostrava claramente que tinha amizade àqueles tipos humildes e muito pobres” (ANTÔNIO, 1977, p. 45). A partir desse momento, a descrição física dos lugares começa a ser gradualmente substituída pela construção de uma representação da personalidade do escritor pré-modernista. Na sequência, o narrador diz:

Dizem agora mulato genial e beberrão. Não concordo com o beberrão. Lima jamais tomou um porre. Nunca perdia a linha, o equilíbrio, não chamava ninguém para ir lá fora, discutir. Jamais gritava, nem nunca o ouvi dizer um palavrão ou um desaforo. Bebia tristemente, tanto que o seu estado era sorumbático, ficava recolhido, olhando vagamente, respondendo quando se lhe perguntavam e, lá uma vez ou outra, dava um aparte. Mas tudo sério, limpo e sensato. E dito o que tinha a dizer entrava na situação sorumbática. Não era brilhante, mas muito sensato. E em estado normal, se 
fosse a uma tribuna, seria brilhante. Mas brilhante assim com brilho e humor. Não era espirituoso, não perdoava os trocadilhos e, no entanto, era amigo dos profissionais do trocadilho - Calixto, Raul Pederneiras, Luiz Peixoto e os caricaturistas em geral. Era bem humorado, no fundo (ANTÔNIO, 1977, p. 50).

Nota-se que a citação de Antônio invalida o próprio título Calvário e porres do pingente Afonso Henrique de Lima Barreto do romance; a não ser que o mesmo seja uma hipérbole sobre Lima Barreto. O depoente informa que Lima vivia na Zona Norte e todos os dias voltava para casa, embora sempre de madrugada, e que não tinha nenhuma implicância contra o bairro burguês de Botafogo ou qualquer outro bairro. Da casa para o centro, a sua condução era o bonde "Inhaúma-Todos os Santos” (ANTÔNIO, 1977, p. 51). Além disso, “em seu roteiro de andanças, dificilmente passava da Zona Centro do Rio” (ANTÔNIO, 1977, p. 52). Adiante o narrador salienta mais uma qualidade de Lima ao apontar que ele "jamais foi visto beber a crédito. Nas rodas, ou os amigos pagavam ou ele pagava” (ANTÔNIO, 1977, p. $54)$.

Os encontros duraram desde 1916 até 1919 e, depois, “foram-se diminuindo as reuniões, a turma se esparramou pelos trabalhos ou foi também dizimada pela gripe espanhola no segundo semestre de 1919. A roda morreu espontaneamente” (ANTÔNIO, 1977, p. 69). A partir desse ponto, o narrador passa a discorrer sobre Lima Barreto, iniciando-se pela seguinte definição do mestre:

A minha definição de Lima: visto em qualquer lugar, ou sentado ou em pé ou passando no meio do grupo, ninguém veria em Lima um homem fora do comum. Era mesmo, à primeira vista, o tipo do mulato comum brasileiro, de situação modesta e, deveria presumir-se senão um inculto, um indivíduo de instrução elementar. A única nota marcante de sua identidade era o olhar: olhos alongados, de um verde sujo com fundo amarelo e embaciados, digo, baços. Eram olhos tristes (ANTÔNIO, 1977, p. 70).

Da citação acima em diante, a representação que o narrador constrói sobre o estimado escritor passa a ocupar amplamente a instância narrativa. Ele diz que "nas rodas que o conheci, sempre foi tratado como irmão. Mas ele se ressentia do preconceito a prova é que jamais frequentou os salões da sociedade” (ANTÔNIO, 1977, p. 73). A qualidade intelectual do escritor pré-modernista de bom leitor e orador é registrada na seguinte citação:

era um erudito bem informado a respeito das grandes doutrinas, manipulando-as, no decorrer da conversa tão adequadamente e com tanta sufísia de substância que, para 
muita gente, uma ou duas horas de contato valiam por lições facilmente compreendidas (ANTÔNIO, 1977, p. 75).

Seguindo, conta-nos que Lima usava roupas modestas, fumava muito e "como todo intelectual, ele tinha sempre os bolsos cheios de papéis e, no pequeno bolso externo do paletó, chamado bolso do lencinho, guardava o seu dinheiro” (ANTÔNIO, 1977, p. 76). A narrativa é finalizada através de um relato sobre um específico encontro que Carlos Alberto Nóbrega da Cunha - o narrador - teve com Lima e Moacir de Almeida num café em Vila Isabel. Nesse incidente, Carlos da Cunha pergunta ao escritor sobre os motivos que o levaram a abandonar os estudos e a abdicar do modesto emprego na secretária do Ministério da Guerra. "Formulada a pergunta, ele não se recusou a falar com franqueza. E disse, em resumo, o seguinte: tudo foi apenas o resultado de uma paixão” (ANTÔNIO, 1977, p. 87).

Ao término do depoimento de Carlos da Cunha, o romance finaliza-se pela citação pertencente ao prefácio de Histórias e sonhos:

\begin{abstract}
Parece-me que o nosso dever de escritores sinceros e honestos é deixar de lado todas as velhas regras, toda a disciplina exterior dos gêneros e aproveitar de cada um deles o que puder e procurar, conforme a inspiração própria, para tentar reformar certas usanças, sugerir dúvidas, levantar julgamentos adormecidos, difundir as nossas grandes e altas emoções em face do mundo e do sofrimento dos homens, para soldar, ligar a humanidade em uma maior, em que caibam todas, pela revelação de almas individuais e do que elas têm de comum e dependente entre si.
\end{abstract}

...assim como querem todos os mestres, eu tento também executar esse ideal em uma língua inteligível a todos, para que todos possam chegar facilmente à compreensão daquilo a que cheguei através de tantas angústias. No mundo não há certezas, nem mesmo em geometria (Amplius, in Histórias e sonhos, 31/8/1916) (ANTÔNIO, 1977, p. 89-90).

O epílogo do romance reatualiza a crítica que Lima Barreto faz a propósito da estética parnasiana em voga no período do pré-modernismo brasileiro. O autor desaprova os escritores que privilegiam as formas perfeitas reminiscentes das idealizações construídas sobre o mundo clássico. João Antônio, ao recuperar essa passagem de Barreto, aponta para os leitores que, no âmbito da escrita literária, a forma não deve ser mais importante que o conteúdo. Além disso, ambos - tanto Antônio como Barreto - chamam a atenção para o papel do escritor na sociedade moderna, ou pós-moderna, como quer Hutcheon e outros. O escritor, através da literatura, deve humanizar o mundo, torná-lo objeto de reflexão para suscitar possíveis mudanças sociais, uma vez que neste não há certezas, mas sim probabilidades. 
Nessa perspectiva, depreende-se que o romance apresenta um conceito de literatura perpetuado pelas correntes teóricas sociológicas dos estudos literários.

\section{Considerações finais}

O romance não segue uma ordem cronológica dos eventos expostos, ocorrem avanços e recuos no itinerário de Barreto. Além disso, sucedem-se digressões a propósito de Lima ou de algum dos seus companheiros no meio da narração. A temporalidade da narrativa se expressa em dois momentos específicos: a primeira frase sobre Lima Barreto do narrador personagem Carlos da Cunha, “conheci-o por volta de 1916”, estabelece o primeiro marco temporal (ANTÔNIO, 1977, p. 21). Sabe-se que Barreto falece em 1922; deste modo, o relato poderia abranger no máximo o período de seis anos sobre o escritor. No entanto, perto do final do romance, o mesmo narrador registra o segundo marco de tempo ao informar que "no ano de 1920 houve menor número de reuniões” entre Lima e os seus companheiros (ANTÔNIO, 1977, p. 80). Portanto, a obra abrange cerca de quatro anos da vida de Barreto.

A arquitetura do romance revela-se bastante complexa estilisticamente. A disposição dos textos na obra tenta promover um arco narrativo homogêneo cujo sentido ressoa simultaneamente como um quebra-cabeça constituído pela intertextualidade difícil de montar durante o processo de leitura. Tal fato salienta o método de edição proposto por João Antônio ao registrar que "como um montador de cinema, tesoura em punho, dei ritmo e respiração ao trabalho alheio” (1977, p. 17). O único texto que apresenta sentido próprio nesse mosaico é a narrativa central do depoente Carlos da Cunha. Portanto, essa instância pode ser lida isolada das demais partes, sem que fique comprometido o seu sentido intrínseco.

Segundo Esteves, "uma leitura mais atenta do livro de João Antônio permitiria afirmar que o texto que está por trás tanto do roteiro de Nóbrega da Cunha quanto da construção de Lima Barreto é A vida de Lima Barreto, de Francisco de Assis Barbosa (1952)” (2010, p. 97). Nesse sentido, o que faz João Antônio é reforçar a imagem estabelecida pela referida biografia de Lima Barreto e, posteriormente, pela crítica e historiografia literária nacional.

Conforme o esquema proposto por Menton, o novo romance histórico apresenta algumas das seis características anteriormente citadas. Essas peculiaridades possibilitam que o pesquisador verifique o grau de distanciamento que as novas narrativas históricas estabelecem em relação ao romance histórico tradicional. A obra de João Antônio exibe nitidamente quatro 
das seis características mencionadas. Em suma, temos no romance a primeira, a terceira, a quarta e a quinta.

A primeira se refere à subordinação, em diferentes graus, da reprodução mimética de um determinado período histórico para apresentação de algumas ideias filosóficas aplicáveis a períodos do passado, presente e futuro. Observa-se na obra de João Antônio que o personagem protagonista Lima Barreto transita pelas distintas classes sociais do Rio de Janeiro através da entrada em bares, cafeterias, restaurantes e livrarias. Deste modo, depreende-se que o autor sublinha as desigualdades sociais expostas no espaço carioca do início do século XX. Pode-se dizer que a literatura, ao apontar essa disparidade social, reflete sobre as diferenças econômicas das classes e sugere que pensemos sobre tal situação. A ideia mostra-se de forma evidente no final do romance, quando João Antônio cita uma passagem do prefácio de Histórias e sonhos. Nesta encontra-se a perspectiva sociológica de literatura concebida por Lima Barreto.

A terceira característica registra a ocorrência da ficcionalização de personagens históricos bem conhecidos, ao contrário da fórmula de Scott, cujos protagonistas são fictícios. Atualmente, sabe-se que a historiografia literária brasileira, em geral, considera Barreto um dos principais romancistas do período pré-modernista, ao lado de Euclides da Cunha, Graça Aranha e Monteiro Lobato. Portanto, trata-se de um escritor canônico conhecido no âmbito da nossa tradição literária, apesar de Antônio dissertar que tanto Lima Barreto quanto suas obras careciam de pleno reconhecimento artístico na década de 70 .

No romance em exame, Lima Barreto assume a condição de protagonista do roteiro arquipoético descrito por João Antônio. Interessante observar nessa construção mimética é que o personagem Lima Barreto é revestido de atributos exclusivamente positivos, sem transparecer nenhuma falha na sua constituição moral. Essa mimese denota uma idealização romântica por parte de João Antônio sobre a personalidade de Barreto.

A quarta característica aborda a metaficção e/ou os comentários do narrador sobre o processo de criação da obra. Observa-se claramente esse traço no segundo texto titulado “Nota prévia”, em que João Antônio esclarece para o leitor a gênese do próprio romance, cuja semente reside no depoimento recebido de Carlos da Cunha, colega de estadia no Sanatório. Do mesmo modo, Antônio faz um paralelo entre a montagem cinematográfica que se dá por cenas e quadros, com a composição dessa narrativa que se constitui arquitetada por recortes e citações originadas na maioria da prosa barretiana.

A quinta característica enunciada por Menton, que aponta a presença constante da intertextualidade no âmbito da poética do pós-modernismo, talvez seja a marca mais 
significativa de Calvário e porres do pingente Afonso Henrique de Lima Barreto. Provavelmente, este é o romance brasileiro que possui mais intertextos do mesmo autor em um romance de outro. A obra destaca abertamente quatro romances de Barreto: Triste fim de Policarpo Quaresma (1915) com sete citações; Vida e morte de M. J. Gonzaga de Sá (1919) com seis; Recordações do escrivão Isaías Caminha (1909) e Clara dos anjos (1948) com cinco. Os últimos três podem ser interpretados como romances que trazem consideráveis traços biográficos do escritor.

Pode-se afirmar que João Antônio, através desse romance, inaugura uma ruptura no âmbito da tradição literária brasileira, uma vez que é a primeira narrativa histórica a colocar um escritor do cânone nacional na condição de personagem protagonista da intriga. Não se encontram casos precedentes do uso desse recurso na história do romance brasileiro. O próximo autor a utilizar esse procedimento, de forma qualitativa, criativa e inovadora, é Silviano Santiago, no romance Em liberdade, de 1981. Trata-se de uma construção narrativa que se dá sob a forma de um diário ficcional escrito por Graciliano Ramos nos seus primeiros meses de liberdade.

Calvário e porres do pingente Afonso Henrique de Lima Barreto, de João Antônio, ao estabelecer a referida ruptura e apontar um novo caminho no nosso sistema literário, por consequência, inaugura também a série de romances históricos que dialogam com a história da literatura brasileira. A partir desse momento, alguns autores irão produzir obras que podem apresentar no seu conjunto uma possível história da literatura nacional através da sua própria ficção histórica.

\section{Referências}

AGUIAR, F. Um escritor na República das Bruzundangas: entrevista com João Antônio. Movimento. São Paulo: Ática, 1993.

ANTÔNIO, João. Calvário e porres do pingente Afonso Henrique de Lima Barreto. Rio de Janeiro: Civilização Brasileira, 1977.

- Conheçamos Lima Barreto, um descobridor do Brasil. In: Crônicas escolhidas: Lima Barreto. Folha de São Paulo. S. Paulo: Ática, 1995.

ESTEVES, Antônio R. O romance histórico brasileiro contemporâneo (1975-2000). São Paulo: Ed. UNESP, 2010.

HUTCHEON, Linda. Poética do pós-modernismo: história, teoria e ficção. Rio de Janeiro: Imago Ed., 1991. 
LUKÁCS, Georg. O romance histórico. São Paulo: Boitempo, 2011.

MENTON, Seymour. La nueva novela histórica de la América Latina (1979-1992). México: FCE, 1993. 